\section{The effects of a clinical ladder program on professional development and job satisfaction of acute care nurses}

\author{
Yolanda A Coleman* and Romy Desai \\ College of Nursing, Chicago, USA
}

Nurses play a vital role in acute care hospitals and health care delivery. The purpose of this research study is to identify the nurse's perception of the Clinical Ladder Program at their hospitaland the correlation ithas on thenurse's job satisfaction and their professional development. A quantitative study will be conducted using two convenience samples from Alexian Brothers Hospital and Saint Anthony's hospital with a total of 52 nurses who are currently participating in the clinical ladder program. The results of this research should be used as opportunities for improvement within the nursing profession at an acute care hospital. This project is beneficial in advancing nursing knowledge and practice because many nurses do not understand why participating in this advancement program can positively impact many aspects of their role at work aside from being a nurse, such as role and identity development at their workplace. Implementing clinical advancement programs in a facility can also increase quality of patient care delivery by retaining excellent nurses. These nurses can demonstrate their It is important in the field of nursing to actively seek improvement and education in practice to keep up with the new evidence-based research practices that are developed daily. The Clinical Ladder Program has become a widespread program in various acute care hospitals for nurses to increase their professional role development.

The ladder system became popular in the 1970s when there was a nursing shortage [1]. The clinical ladder is a structured system to provide nurses' career advancement while remaining in their current clinical setting, providing direct patient care. It is used to recognize professional development and differentiate between different levels of nursing care and expertise. The purpose of the clinical ladder is to recognize and incentivize these staff members who are developing their profession. It also helps in retaining the nurses and decreases turnover rates [2]. Furthermore, it enhances nursing job satisfaction, which is specifically what this research study is focused on. Job satisfaction leads to

\section{More Information}

*Address for Correspondence: Yolanda A Coleman, Assistant Professor, College of Nursing, Chicago, USA, Tel: 773.235.5533, 708334-9757; Email: yolanda.coleman@resu.edu

Submitted: 19 July 2019
Approved: 25 July 2019
Published: 26 July 2019

How to cite this article: Coleman YA, Desai R. The effects of a clinical ladder program on professional development and job satisfaction of acute care nurses. Clin J Nurs Care Pract. 2019; 3: 044-048

DOI: 10.29328/journal.cjncp.1001016

Copyright: Coleman YA, et al. This is an open access article distributed under the Creative Commons Attribution License, which permits unrestricted use, distribution, and reproduction in any medium, provided the original work is properly cited

Keywords: Nurse job satisfaction; Clinical ladder program; Nurse job development

Check for updates

increased retention and decreases the turnover rates. The cost of nurse turnover can have a huge impact on a hospital. According to the 2016 National Healthcare Retention \& RN Staffing Report, the cost of turnover for a nurse ranges from $\$ 37,700$ to $\$ 58,400$. Hospitals can lose $\$ 5.2$ million to $\$ 8.1$ million annually when nurses quit, and after training.

Nurses are an integral part of the health system and it is important to continue their clinical expertise and enhance their education continuously. The nursing profession is a constantly changing environment requiring research and education. This research could be well spread to other nurses by having nurses educate each other. One way this can happen is through a clinical ladder program. Not only does it benefit the nurses by increasing their pay, but it benefits the hospital and the patients by providing them with quality care. Continued professional development is accomplished in various ways. At times, nurses have competencies that are to be completed online and other times they have in-services. The newest evidence-based practice should be implemented in their holistic care through new protocols and practices. Different hospitals have different programs developed and put in place for their employees to participate in. The most popular and longstanding is the clinical ladder system. There are certain requirements to participate such as months of employment, and years of experience as a registered nurse. 
Participation is not mandatory, and nurses can be selected to join and others can apply on their own will. The different levels of the clinical ladder program are clinician level one through four. These levels are based off the nursing theorist Patricia Benner's theory Novice to Expert. The model in summary states that an individual starts off in the novice stage and ends up in the expert realm as new skills and knowledge are gained. The Benner model has been used extensively as rationale for career development [3].

The five stages of expertise in the novice to expert model are: novice, advanced beginner, competent, proficient, and expert. The application process for the clinical ladder system may consist of filling out an application form, submitting a recent resume, letters of recommendations, and a narrative essay explaining your involvement on the nursing unit. After selection into the program, a participant may submit an education or research project, education to staff, community service hours, training of other staff, and other requirements based on the program. This topic of implementing a clinical ladder program is important. If hospitals have a low job satisfaction rate for nurses, this could negatively impact several aspects of the hospital and patient care; and affect the potential for success for the hospital. It could lead to disconnected employed nurses and declines in patient safety and quality of care. Using data from the American Nurses Association's National Database of Nursing Quality Indicators (as cited in AMN Healthcare), researchers discovered that a "25 percent increase in nurse job enjoyment over a twoyear span was linked with an overall quality of care increase between 5 and 20 percent". It is important to investigate what can increase a nurse's job satisfaction and implementing a clinical ladder program can lead to that progression. Data from this research study will add to the existing knowledge of factors that increase a nurse's job satisfaction in the acute impatient role and provide a way to retain nurses.

\section{Research Statement}

The purpose of this project is to determine how the clinical ladder affects the nurse's job satisfaction and professional role development. The researcher's question is, "How will an acute care nurse's participation in the clinical ladder program affect their professional development and job satisfaction?" The hypothesis is that participating in the clinical ladder program at their hospital would increase their job satisfaction by participating in a program that develops their role professionally.

\section{Literature review}

A literature review was completed using three studies. Exploring current literature related to this topic is necessary to figure out where to focus on the most current research. Nurse satisfaction is a critical issue that should be addressed when examining retention rates for nurses. It is one of the major factors that influence whether a nurse quits the job or stays in the unit. One study conducted by [4] was completed in Malaysia. This study looked at the nurse's job satisfaction perception and if that correlated with their intent to leave their position. The study consisted of 150 nurses that were selected with a simple stratified sampling method and out of those 150, 141 questionnaires were returned with answers. These nurses worked in units like the critical care unit, trauma or the emergency room. Each of the nurses had a code assigned to them so they would remain anonymous. The questionnaire had 60 questions and a Likert scale was used for the answer choices. Several analysis methods were used to analyze the data such as the chi-square test to correlate between the demographic variables and the intent to leave the organization. A multivariate analysis of variance test was used also. It was a cross-sectional study that resulted in showing that nurses had an overall moderate level of job satisfaction. It also showed that one of the factors, professional development, led to higher job satisfaction. This indicates that hospitals that offer opportunities for promotions or career advancement/professional development may lead to a higher job satisfaction for nurses. [5] Conducted a study called, "Nurses' Perception of Clinical Ladder Programs". This study was completed to discover the nurses' viewpoints on the clinical advancing system and if the ladder program successful addresses what motivates and satisfies nurses. Only 30 of the nurses in the study, where population size was $68,44.1 \%$ of the sample worked at a hospital with the clinical ladder program instilled. The survey used the Likert scale in which 1-is strongly disagree and 5 - is strongly agree. The nurse's total perception of the clinical ladder program from a 1-5 scale was 3.44. It also found to be true that nurses value the responsibility and accountability of their job more than the recognition of the clinical ladder levels [5]. Although it would have been beneficial to know which type of units these nurses were in and which type of hospital, the study overall was a starting point in researching the amount of participation in the clinical ladder and the positive outlook and perception of the ladder.

One of the goals of a clinical ladder program in nursing is to ensure empowerment. These nurses are using their nursing license to its fullest capability and are making more decisions at the bedside using evidence-based practice, implanting new ideas to the unit they work on. They are working alongside management to improve the patient satisfaction at the same time. Another literature review was completed on a study that examined the relationship between the nurse's intent to stay and their view on empowerment in their practice. This study used Kanter's framework and Theory of Organizational Empowerment to determine if power and opportunity was in place, the degree of power in that workplace would correlate to their level as a nurse. The study consisted of 147,320 nurses in Florida and a random sample of 500 nurses were sent a questionnaire in which 206 were returned. The Conditions of Work Effectiveness 
Questionnaire designed by Chandler in 1986 was used for this study. Four structures within the empowerment realm were measured: opportunities, resources, information, and support [6]. The study showed that a moderate amount of empowerment was perceived at their workplace. This shows that an increased amount of empowerment was still needed at their workplace which can be accomplished with more opportunities, resources, information and support. Structural and organizational empowerment increases job satisfaction which in turn decreases the turnover rates for nursing staff [6]. This empowerment can be administered to nurses by participating in the clinical ladder program.

\section{Conceptual framework}

A theoretical concept that guided the research for this investigation is Frederick Herzberg's Motivation-Hygiene theory also known as the Two-Factory Theory. In the 1950s-1960s he set out to determine what resulted in employee satisfaction and dissatisfaction. The results of his findings were that certain factors of a job are consistently related to job satisfaction, while some other concepts are related to job dissatisfaction. Some factors for satisfaction are achievement, recognition, the work itself, responsibility, advancement, and growth [7]. In this theory, he refers to motivation factors as the job satisfiers that are mostly intrinsic and hygiene factors as the job dis satisfiers, which are mostly extrinsic factors at work.

\section{Research design}

A descriptive design was used for this cross-sectional study to survey acute care nurses who are currently participating in the clinical ladder program. One research questionnaire was sent out in an email and the nurses voluntarily and anonymously participated. The sample was a convenience sample obtained by asking the clinical managers of that unit for the names and emails of the nurses who are currently participating in the clinical ladder program at the hospital. The Likert scale was used in the questions to calculate and analyze the job satisfaction score more easily. The data collected was quantitative data. The platform used to collection the data for this research was a website called SurveyMonkey. SurveyMonkey is a data collection online website where one can design a survey and email it and distribute it to the subjects.

\section{Sample}

Two convenience samples were obtained from the two principal investigator's places of work - Alexian Brothers Medical Center and Saint Anthony's Hospital. The participant's names and emails were obtained from the manager of that specific unit. After the names are obtained, the survey was emailed to those nurses only. These nurses were both male and female and ranged from 23 to 50 years of age and were nurses who currently participate in the clinical ladder program at their hospital. These nurses work in the acute care impatient setting in the hospital.

\section{Protection of human rights}

This study was reviewed by the Institutional Review Board of Resurrection University and approval was granted. The participants remained anonymous. By completing and submitting the questionnaire the nurses consented to the study and for data to be collected from the participant. Informed consent was made online before the initiation of the survey on the website. No physical form was given to the participant before the start of the study. At the beginning of the study the investigator added a consent statement (Appendix A). There was a yes or no question asking if they consented to the statement and if they wished to proceed with the survey. No identifying characteristics or names were used in representing the data of this research study. The investigator also included the link to SurveyMonkey's privacy policy (Appendix B).

\section{Risks and benefits}

Participation in the study would contribute to research that shows how the clinical ladder program influences nurses who participate in the program. The only risks to participation in the study were those associated with an online survey. The participant was not asked to report on sensitive topics or emotionally distressing topics. The risk of psychological effects from the study were minimal to no risk. The managers of the unit at each hospital did not obtain the scores of the participant's answers on the survey so the risk for anxiety to answering a questionnaire at their place of work was at minimal to no risk.

\section{Data storage}

The participants would not be identified by name at any point in the research findings. The data was securely stored and encrypted on the SurveyMonkey database. The only individual with access to the data was the principal researcher. The participant was not identified during the research process and data collection. The data was destroyed within two weeks of the survey completion after all the data was analyzed by the principal investigator.

\section{Participant withdrawal statement}

The participant had the right to refuse or withdraw from this study at any point in time. One way to do this was to simply ignore the invitation to participate in the email and survey invitation. There was no penalty if the participant chose not to participate in this study. No consequences or reparations were taken at their place of work for either participating or not participating in the study.

\section{Data collection methodologies}

A descriptive cross-sectional study design was used for this research analysis. A quantitative analysis was performed for this study. Nurses from two hospitals completed a questionnaire on one occasion. The respondents were nurses who worked in an acute impatient setting. The survey was 
carried out at two hospitals, Saint Anthony's and Alexian Brothers Medical Center. Both hospitals have implemented a clinical ladder program and only nurses participating in the program were invited to participate. A questionnaire was made with 17 questions about how the nurses were satisfied in their job and how their professional role development was carried out in their place or work. That survey was inputted into the SurveyMonkey. The survey was only emailed and needed to be submitted online. No physical form was given to the nurses. Two weeks was assigned to the study time to collect adequate data. The survey questions were created by the primary investigator. The survey was standardized for the two different hospitals. No other recruitment methods were used in this research study such as advertising or announcements. A goal of 50 responses was to be attained from the nurses but in the end, the sample size was determined by the number of nurses that submitted the completed survey before the end of the research period. The SurveyMonkey survey was emailed to the nurses by providing them with the link. The first question of the survey was their consent to participate in the study. After they agreed to the consent, they proceeded on with the survey. First, the researcher had to create an account with the website and design the survey with the multiple-choice answers by using a template. The link to the survey was copied and pasted and distributed to the nurses via email. The data was analyzed in a way that no personal identification was shown. The Likert scale was used to showcase the nurse's satisfaction and to make it easier to analyze using statistical tests. The research was analyzed using the quantitative data obtained from the participants' results. Graphs and charts will be made using the data obtained from the study. The dependent variable is job satisfaction and professional development. The independent variable is that they are participating in the clinical ladder program. The Likert scale will be transformed into ratio data by using a 1-5 scale. (1=strongly disagree, $2=$ disagree, $3=$ =neutral, $4=$ agree, $5=$ strongly agree). Descriptive analysis method was used to calculate the means, standard deviation and variances of the sample data.

\section{Data Analysis Methodologies and Results}

In this research work, the data was analyzed using descriptive analysis method. Mean, median, and mode calculations were made where necessary. Biographic and population data will be represented in a chart and other graphs. Most survey respondents were between ages of 2328 years of age (28.5\%) where the sample size was 52 nurses (Table 1). No doctoral prepared nurses participated in the survey. Bachelor's prepared nurses were $78.85 \%$ of the participants (Table 2). The reasoning why most nurses join the clinical ladder at their hospital is to advance their skills and career development (52\%) as well as the increase in pay (30\%). Although there was no strong positive correlation between the level of clinical ladder and the increase in job satisfaction (correlation coefficient $=0.29$ ), there was

\begin{tabular}{|c|c|c|}
\hline Table 1: Sample age range. & & \\
\hline Age range & Percentage & Responses \\
\hline $23-28$ & $28.85 \%$ & 15 \\
\hline $29-34$ & $26.92 \%$ & 14 \\
\hline $35-40$ & $17.31 \%$ & 9 \\
\hline $40-45$ & $15.38 \%$ & 8 \\
\hline$>50$ years of age & $11.54 \%$ & 6 \\
\hline
\end{tabular}

Table 2: Education level.

\begin{tabular}{|c|c|c|}
\hline Level & Percentage & Responses \\
\hline Associates degree & $7.69 \%$ & 4 \\
\hline Bachelor's degree & $78.85 \%$ & 41 \\
\hline Master's degree & $13.46 \%$ & 7 \\
\hline Doctorate degree & 0 & 0 \\
\hline
\end{tabular}

positive evidence that these nurses who are participating in the clinical ladder at any level are overall satisfied with their job as a nurse with a percentage of $65.38 \%$ saying that they are satisfied and $15.38 \%$ saying they are very satisfied. The mean score of the nurse's overall satisfaction score as a nurse was 3.88 with a score of 5 being very satisfied. Most of the nurses also agreed that they have a sense of empowerment on their unit (48.08\%), and $73.08 \%$ of the nurses either strongly agree or agree that they feel free to express their opinions, contribute ideas and set personal goals in the workplace. This is a positive rating because this would in turn increase employee retention. Not only are the nurses satisfied in their role as a nurse, but also satisfied in the quality of care that they provide to the patients. About $28.85 \%$ strongly agreed that they are satisfied in the care they provide the patients and 57.69\% agreed. According to the research study, participating in the clinical ladder program led to $40.38 \%$ of the nurses to say that they intended to stay in their current position while the other $30.77 \%$ wanted to stay in the nursing field but leave direct patient care at the bedside.

\section{Discussion of findings}

The results of this study show that having a clinical ladder in a healthcare institution leads to nurses being satisfied with their work and leads them to have a sense of empowerment and leadership. The clinical ladder program level does not correlate with increased satisfaction of the nurses, but merely just participating in the program shows a relatively high satisfaction level. According to [8], employees who are satisfied with their work tend to stay longer and are more likely to be part of an engaged workforce. The clinical ladder program allows nurses to use their evidence-based research skill to guide their nursing practice further and be more involved in their unit in which they work. Findings showed that nurses originally joined the clinical ladder program for hopes of advancing their skills and career development (52\%).

\section{Limitations}

The sample size obtained for this research study was a limitation. A larger sample size and more respondents to 
the study would have given more insight into this study and confirmed its validity. Also, time was a limitation for this research study. More time for the registered nurses to respond to the questionnaire would have led to an increase in sample size for the research analysis and more depth into the research findings. For a survey that is conducted online, a response rate of $20 \%$ is considered as a good response rate while a $30 \%$ response rate is more reliable and better [9]. One might say that this sample only represented the geographic location of the Chicago land area. Expanding the research to various other states could lead to an increased sample size and a more thorough research method. Analyzing the difference between two populations, one hospital having a clinical ladder, and one that does not have, would be beneficial to see the immense difference in nursing satisfaction in nurses and the increase in their professional role development.

\section{Implications for nursing practice and recommendations}

Researching the clinical ladder and its impact on nurse's job satisfaction is beneficial in advancing nursing knowledge and practice because a lot of nurses do not understand why participating in this advancement program can positively impact many aspects of their role at work aside from being a nurse. It can lead to increased job satisfaction and retention. Not only do these programs affect nurses themselves, but also the hospital as far as revenue [10]. Aside from that, implementing these types of programs in a facility can increase quality of patient care delivery. It is important in the field of nursing to actively seek improvement and education in our practice. This is a great way to implement that. The research gathered from two convenience samples will further be analyzed to see how exactly this is currently affecting nurses that are working in an acute care setting. This research will further urge nurses to partake in this great opportunity that can be beneficial in a variety of ways. Further research on this topic should take place between the nurse's satisfaction in different high stress environments in the hospital such as intensive care unit and the emergency department. Higher stress environments have more potential for burnout and decreased retention than lower stress environments. Nurses feel that that their care is inadequate in quality for what their patient's demand which increases the turnover rate [11-13]. For hospitals that are looking to vamp their clinical ladder or create one, they can tailor it unit - specific depending on the unit's stress level. Retention of nurses is a global problem that needs to be researched more and the researcher is hoping this study will help close an existing knowledge gap on some of the research.

\section{Conclusion}

The purpose of this descriptive research study on the clinical ladder program was to analyze the impact clinical ladder participation had on the nurses working in their specific unit and how it impacted their job satisfaction and professional role development. This study which consisted of 52 nurses would have been more powerful and informative with a larger sample size and with a comparison population of nurses who worked in a hospital with no clinical ladder program. All hospitals should have this structural program to encourage empowerment and increase nurse retention. Some hospitals are dissolving the clinical ladder program in hopes of saving money. This program can increase nurse retention by increasing nursing satisfaction and role development. This could potentially save the hospital money in the long run by not hiring new employees as frequently, losing money on orientation, and training of nurses who turnover. Nursing clinical ladder programs and other clinical leadership opportunities will keep nurses interested in the ever-growing profession.

\section{References}

1. Pierson MA, Liggett C, Moore KS. Twenty years of experience with a clinical ladder: A tool for professional growth, evidence-based practice, recruitment and retention. J Contin Educ Nurs. 2010; 41: 3340. PubMed: https://www.ncbi.nlm.nih.gov/pubmed/20102141

2. Smith N, Karakashian AL. Clinical ladder: Strategy in professional development. 2017.

3. Benner P. From novice to expert: Excellence and power in clinical nursing practice. New Jersey: Prentice Hall. 2001.

4. Ramoo V, Abdullah KL, Piaw CY. The relationship between job satisfaction and intention to leave current employment among registered nurses in a teaching hospital. J Clin Nurs. 2013; 22: 3141 3152. PubMed: https://www.ncbi.nlm.nih.gov/pubmed/24118518

5. Baucom B. Nurses Perception of Clinical Ladder Programs - Graduate thesis. Nursing Theses and Capstone Projects. 2012.

6. Nedd N. Perceptions of empowerment and intent to stay. Nursing Economics. 2006; 1: 13-19.

7. Gitman LJ, Mc Danaiel C, Shah A, Reece M, Koffel L, et al. Open Stax Introduction to business. 2018.

8. Harter JK, Schmidt FL, Agrawal S, Plowman S. The relationship between engagement at work and organizational outcome: 2012 Meta-analysis. 2013.

9. Van Dessel G. How to determine population and survey sample size? 2017.

10. Smailes $\mathrm{P}$, Blumenauer $\mathrm{C}$, Bookless $\mathrm{H}$. Clinical research nurse career advancement using clinical ladder programs. Clinical Researcher. $2017 ; 31$.

11. Khanade K, Sasangohar F. Stress, Fatigue, and Workload in Intensive Care Nursing: A Scoping Literature Review. Proceedings of the Human Factors and Ergonomics Society Annual Meeting. 2017; 61: 686-690.

12. AMN Healthcare. Job satisfaction for nurses helps enhance patient outcomes. 2013.

13. Nursing Solutions Inc. National Healthcare Retention \& RN Staffing Report. 2016. 